\title{
Research on the Cultivating Model of Talents with Internationalized Perspective for Teaching Chinese as a Foreign Language
}

\author{
Wei-yan MA \\ Bohai University, Jinzhou, Liaoning Province, China
}

\begin{abstract}
Keywords: Cultivating Model; Internationalized Talents; Teaching Chinese as a Foreign Language; Intercultural Communication.
\end{abstract}

\begin{abstract}
Students who graduated from major of Teaching Chinese as a Foreign Language are aimed to teach foreign students, which means that they not only need the knowledge of their major but also need the internationalized perspectives and intercultural communication skills to be qualified teachers. This paper mainly focuses on how to design suitable cultivating model for these Chinese students and provides practical ways to make the students have the desire to communicate with foreign students and have the ability to guide and accomplish assignments with foreign students.
\end{abstract}

\section{Introduction}

In recent years, with the further development of global economic integration and China's opening to the outside world, people from different walks and from different countries, can do face-to-face communication with each other much more easily. They can also exchange information anytime and anywhere via the Internet. The frequent communication increasingly highlights the need to understand diverse cultures and the urgency to improve internationalized talents. "We are now entering a globalized era, which means that the people we are communicating are not refined to Chinese, thus we need to cultivate more internationalized talents" said Wang Huiyao [1], director of the research center for China and Globalization and a senior visiting fellow at Harvard University. Dr Susan Sclafani, a former minister of US education, said: "with the rise of the new economy, the global economy is undergoing a rapid transformation, which will determine the new requirements for the quality of talents in the world over the next 30 years, that is, the need for multilingual communication, teamwork and cultural awareness among employees from different countries.'[2] All of these mean that enterprises require university graduates to have more ability to innovate and to develop comprehensively. In the current college teaching reform environment, the cultivation of international talents has attracted extensive attention. More and more people also realize that higher education should include the goal of cultivating international talents.

As a major of Teaching Chinese as a Foreign Language which has developed quickly these years with the fast development of Chinese economy, it calls for more and more students with good intercultural communication skills and internalized perspective. Cultivating internationalized college students will definitely enhance the popularity of China and at the same time, promote the development of local economy.

\section{Intercultural Communication Skills}

Intercultural communication refers to the communication process between people with different cultural backgrounds. In recent years, American education intellectuals have come to realize that to cultivate the next generation to become a pillar of the 21 st century, they must have a comprehensive, in-depth and accurate understanding of foreign cultures. Politicians believe that if the next generation can learn to understand the different political systems and religions better, there will be no more wars and even fewer senseless conflicts in the "global village" where we live. In order to make a good reserve of intercultural talents, many universities in the United States have set up courses on intercultural communication.

Deng Yanchang, Gu Jiazu, Hu Chao, Huang Zhan, Kim Y. Y. have seen the importance of 
communication with people from different cultures, Li Bei, Tang Zhenmin, Wang Yunhai, Yang Hongying, Yu Weiqi have raised the importance of cultivating international talents. Chinese colleges and universities are beginning to realize the importance of intercultural communication and offer intercultural communication courses in more majors.[3-12] But on issues such as "international and cross-cultural awareness cultivating" and "enhancement of students' intercultural communication ability" are still far behind. Even now, some people still think it's no need to study courses which are not directly connected with their major. Some students feel that's a little difficult to communicate with foreigners. In fact, language study should not be separated from culture. American linguist Sapir believed that language could not exist without culture [13]. From these, we need to realize that if we want to have good understanding with foreign people we need to have good intercultural communication ability.

In the courses of Teaching Chinese as a Foreign Languages, it is necessary to build a practical teaching link and the second classroom extracurricular practice task in active participation through a variety of teaching methods of comprehensive and flexible use, which will activate for first class and second class teaching atmosphere, and stimulate students' learning initiative, also help the cultivation of students' classroom learning ability and the improvement of the second classroom teaching effect. At present, the paper aims to discuss the characteristics of the courses and the training objectives of students at different levels, and attempts to adopt practical teaching methods. International talent training will be based on the existing courses of Chinese and foreign students and make specific research in the following aspects to achieve good teaching and practical results.

\section{Cultivating Model}

This paper will not only focus on the Chinese students, but also try to connect the Chinese students with foreign students and encourage them to do some first and the second classroom practice activities together. These students can be together to finish courses like "Chinese calligraphy and western painting appreciation", "Chinese folk music and western opera appreciation", "Chinese martial arts", "the writing of Chinese characters", "paper cutting", "Chinese songs", "Chinese and western poems", "Chinese and western drama performing" and other learning and performance activities. Practice implements to every aspect of culture, guiding students to appreciate Chinese and western culture, making the Chinese students know and understand Chinese culture deeply, realize the cultural connotation, and initiative to teach these to their future foreign students. This will make foreign students understand the Chinese culture with happiness, learn knowledge quickly, strengthen the consciousness of participation of students actively, thus to further improve students' language ability and practical communicative ability.

The in-depth exchange opportunities created for Chinese students in class activities and extracurricular activities with overseas students will greatly motivate the learning enthusiasm of Chinese students, cultivate their critical thinking ability and intercultural communication ability, and lay solid foundation for becoming internationalized talents.

Providing Chinese and foreign students with a variety of extra-curricular practical tasks is closely combined with classroom teaching content to improve their ability to solve problems. It will mainly carry out extracurricular practices from the following aspects to achieve the purpose of self-completion, self-learning and self-improvement of students, and lay a foundation for them.

Give students more cooperative and competitive tasks for each course of this major, such as phonetics teaching, Chinese characters teaching, and oral lessons. Provide foreign students with the right tasks to make them truly integrate China with their countries and express themselves at the same time. Then, the group members discuss, share their results or deficiency together. While completing the task, students will improve their language level and enhance their ability of interpersonal communication with Chinese and foreign students. Encourage students to do the tasks not only with reading books but also give them chance to create colorful outcomes to develop their confidence in learning, improve their interest and strengthen their motivation. Students will be required to make attractive personalized products, and encouraged to design interesting games and class activities. At the same time, this will help them to communicate with classmates and fulfill 
their tasks smoothly and confidently.

International students can be divided into different groups, and they will be given different roles. Chinese and foreign students could be the judges to express their idea and make them know their shortcomings. The students may enjoy the "game" and feel the fun of learning knowledge. Encouraging foreign students to break through themselves and form a complementary learning model with Chinese students will benefit both Chinese and foreign students. Organizing foreign students and Chinese students to form teams to compete in various interesting projects will not only be fun but practicing their oral language ability and cooperative communication skills. Participation in singing, lectures and other forms of practical tasks can enable students to think about whether their learning methods are the most effective and whether they can maximize their abilities all the time. Such classes are proved to be popular with students.

Let's take a course that the author has taught as an example. Intercultural communication is a compulsory course for students of Teaching Chinese as a Foreign Language. Both knowledge imparting and ability cultivation are emphasized in teaching, among which the cultivation of practical ability is very important. In practice, the method of combination of inquiry teaching and research teaching is mainly used. During the teaching process, the author took advantage of the advantages of overseas students in the university to invite outstanding overseas students into the classes of Chinese students and arranged interactive tasks in advance. Every group chose a specialized task according to the students' interests. Overseas students participated in each group. The students learned independently, inquiringly and cooperatively, and searched for information in cooperation, and finally presented and communicated in the second class. In this process, students are very active, and the main role of teachers is to guide and organize, summarize and improve the results of each group's exercises, and concentrate on the problems that need to be further improved. In such a second class, teachers, Chinese and foreign students communicate with each other completely. The second class atmosphere is harmonious, students' initiative and creativity are fully mobilized, and the teaching effect is greatly improved.

\section{Conclusion}

To make the students with major of Teaching Chinese as a Foreign Language have an internationalized perspective and provide suitable ways for them to practice is crucial. It still has a long way to go and it needs efforts from both of the students and the teachers in order to cultivate more and more talented people for our country. This paper not only tried to focus on Chinese students but also make a strong tie between Chinese students and foreign students. The author encouraged to break the actual and psychological barriers between them which will benefit not only to the students but to the world. Better communication can make deeper understanding. At the same time, through a good model, the students who have earned a lot will make more people to be internationalized talents.

\section{References}

[1] Wang Huiyao talks about internationalized talents Intercultural communication is the center of mass Tencent Education [Blog] http://edu.qq.com/a/20120505/000061.htm. 2012.05.

[2] Bai Xiao, Guo Yan, Cheng Weihong. College Students' Career Development and Employment Guidance [M]. Shenyang: Northeasten University Press. 2011 (7).

[3] Deng Yanchang, Liu Runqing. Language and Culture [M]. Beijing: Foreign Language Teaching and Research Press, 1997.

[4] Gu Jiazu. Cross-cultural Communication: Hidden Culture in Foreign Languages and Literature [M]. Nanjing: Nanjing Normal University Press, 2000.

[5] Hu Chao. A Survey Report on College Students' Intercultural Awareness and Intercultural Communication Ability [J]. Chinese Foreign Languages, 2005 (3). 
[6] Huang Zhan. New Progress in Foreign Studies on Intercultural Adaptation of International Students in Recent Ten Years [J]. Comparative Education Study, 2014 (08).

[7] Kim, Y.Y. Becoming Intercultural: An Integrative Theory of Communication and Cross-Cultural Adaptation [M]. Thousand Oaks, CA: Sage Publications, Inc. 2001.

[8] Li Bei, Liang Zhiyang. Research on Influencing Factors and Countermeasures of International Talent Cultivation [J]. Beijing Education (Higher Education), 2017 (05).

[9] Tang Zhenmin. Research on International Talent Cultivation Situation and Coping Strategies [J]. Higher Education Exploration, 2016 (04).

[10] Wang Yunhai, Zhang Li, Zhang Nan. Comparative Analysis and Countermeasure Research on Policy Support for International Talent Cultivation [J]. Research Trends of Education Teaching Research in China, 2016 (15).

[11] Yang Hongying, Tong Lu. Mechanism Research on School-enterprise Cooperation in Cultivating International Talents under the Background of "One Belt And One Road" Strategy [J]. Modern Education Science, 2017 (06).

[12] Yu Weiqi. Empirical Research on Intercultural Communication Competence of Chinese Learners in China: Sensitivity and Efficacy [J]. World Chinese Teaching, 2012 (04).

[13] Sapir E. Language [M]. Beijing: The Commercial Press, 1977. 